\title{
Potensi Usaha Perikanan di Desa Kecamatan Bantargadung Kabupaten Sukabumi Provinsi Jawa Barat
}

\author{
[Potential of Fisheries Business in BantargadungDistrict Sukabumi, \\ West Java Province]
}

\author{
Sukma Budi Prasetyati ${ }^{1}$, Nur Baety Alifiani ${ }^{2}$, Lenny S. Syafei ${ }^{2}$, Sobariah ${ }^{2}$ \\ ${ }^{1}$ Dinas Kelautan dan Perikanan Kabupaten Sukabumi \\ Karangpapak, Cisolok, Sukabumi, Jawa Barat \\ 2Jurusan Penyuluhan Perikanan, Sekolah Tinggi Perikanan \\ Jalan Cikaret No. 2, Bogor Selatan, Kota Bogor 16132
}

Diterima : 4 Januari 2019 Disetujui : 1 Maret 2019

\begin{abstract}
Abstrak
Proses atau wadah pembelajaran bagi pelaku usaha maupun pelaku utama yang disebut dengan penyuluhan tidak pernah terlepas dari media yang berkaitan dengan teknologi. Media berperan untuk memperoleh data berupa data geografis maupun informasi yang bersifat umum maupun khusus. Media juga yang berperan penting dalam penyampaian inovasi mengenai teknologi dalam bidang perikanan. Adanya perkembangan teknologi, tentunya memudahkan pengumpulan data dan informasi yang berguna bagi kegiatan penyuluhan yang akan dilakukan. Kecamatan Bantargadung merupakan salah satu kecamatan di Kabupaten Sukabumi yang terdiri dari tujuh desa yaitu Limusnunggal, Buanajaya, Bojonggaling, Bantargebang, Bantargadung, Mangunjaya, Boyongsari. Kecamatan Bantargadung memiliki potensi perikanan di bidang pengolahan ikan pindang dan budidaya dengan komoditas utama ikan lele dan nila. Karenanya metoda penelitian ini adalah mengumpulkan, mengolah serta menyusun data perikanan dan menganalisis permasalahan perikanan di Kecamatan Bantargadung. Penelitian ini dilaksanakan pada tanggal 1-30 November 2018 di Kecamatan Bantargadung. Penentuan sampel menggunakan Rumus Slovin dengan persentase error $20 \%$. Pengumpulan data sekunder dan primer menggunakan dua metode yaitu dengan wawancara menggunakan kuesioner dan observasi langsung ke lapangan. Kecamatan Bantargadung memiliki tujuh desa dengan dua desa yang saat ini kegiatan perikanannya sudah berkembang. Potensi perikanan yang mungkin untuk dikembangkan adalah Pengolahan Ikan Pindang serta budidaya ikan air tawar.
\end{abstract}

Kata kunci: ikan pindang, kecamatan bantargadung, potensi perikanan

\section{Abstract}

The process or container of learning for business actors and key actors called extension services has never been separated from media related to technology. The media plays a role in obtaining data in the form of geographical data as well as general and specific information. Media also plays an important role in delivering innovation regarding technology in the fisheries sector. The development of technology, of course facilitates the collection of data and information needed in the extension activities to be carried out. Bantargadung Subdistrict is one of the sub-districts in Sukabumi Regency which consists of seven villages namely Limusnunggal, Buanajaya, Bojonggaling, Bantargebang, Bantargadung, Mangunjaya, Boyongsari. Bantargadung subdistrict has fisheries potential in the field of pindang fish processing and cultivation with the main commodities of catfish and tilapia. So from that, the author chose Bantargadung District as the research location. The purpose of this research is to collect, process and compile fisheries data and analyze fisheries problems in Bantargadung District. This research was conducted on 1-30 November 2018 in Bantargadung District. Determination of samples using Slovin formula with a percentage error of $20 \%$. Data collected in the form of secondary data and primary data, collected using two methods, namely by interviewing using questionnaires and direct observation to the 
field. Bantargadung Subdistrict has seven villages with two villages which currently have developed fisheries. Potential fisheries that might be developed are the processing of Pindang fish and the cultivation of freshwater fish.

Keywords: bantargadung sub-district, fisheries potential, pindang fish.

Penulis korespondensi

Sukma Budi Prasetyati | sukmabudiprasetyati@gmail.com

\section{PENDAHULUAN}

Setiap waktu perkembangan ilmu pengetahuan dan teknologi mengalami peningkatan. Hal tersebut tidak lain karena inovasi-inovasi terbaru yang dinamis. Era Digital 4.0 tidak hanya berpengaruh pada industrialisasi saja. Era Digital 4.0 ini juga memberikan dampak perkembangan yang baik di bidang penyuluhan perikanan. Penyuluhan yang merupakan proses atau wadah pembelajaran bagi pelaku utama maupun pelaku usaha perikanan tidak pernah terlepas dari media yang berkaitan dengan teknologi (Amanah 2008).

Media diperlukan untuk memperoleh data berupa data geografis maupun informasi. Media juga yang berperan penting dalam penyampaian inovasi mengenai teknologi dalam bidang perikanan. Dengan adanya perkembangan teknologi, tentunya memudahkan pengumpulan data dan informasi yang berguna bagi kegiatan penyuluhan yang akan dilakukan (Rosidawanti, Yunasaf, dan Alim 2014). Hal tersebut yang dijadikan landasan pemilihan terhadap Kecamatan

Bantargadung Kabupaten Sukabumi untuk dilakukan identifikasi potensi wilayah perikanan guna mengetahui potensi SDA maupun SDM serta potensi usaha perikanan yang ada di lokasi tersebut. Tujuan dilakukannya penelitian ini adalah untuk menjabarkan potensi usaha perikanan serta permasalahan yang dihadapi pelaku usaha dan pelaku utama perikanan di Kecamatan Bantargadung.

\section{BAHAN DAN METODE}

Penelitan ini dilaksanakan pada tanggal 1-30 November di Kecamatan Bantargadung. Lingkup kegiatan yang dilaksanakan dalam identifikasi potensi wilayah perikanan di Kecamatan Bantargadung Kabupaten Sukabumi yaitu melakukan identifikasi sumberdaya alam dan sumberdaya manusia, aktivitas produksi, aktivitas usaha dan aktivitas penyuluhan penentuan populasi dengan menggunakan Purposive. Purposive yang digunakan untuk menentukan populasi yang akan diambil sampelnya adalah seluruh anggota kelompok yang 
telah disuluh dan terdaftar di database penyuluh perikanan tahun 2018. Penentuan jumlah sampel responden menggunakan rumus slovin. Pada pelaksanaannya, dipilih dua desa potensial dengan empat kelompok yang berada di dua desa potensial yang dipilih. Pemilihan desa potensial tersebut dilihat dari adanya usaha aktivitas perikanan, serta potensi berupa sumber air yang merupakan media pemeliharaan ikan, serta adanya pasar yang menggerakkan perekonomian pelaku usaha perikanan di Kecamatan Bantargadung. Dalam pengambilan sampel RTP yang dapat mewakili seluruh populasi sebanyak 34 orang. Sampel diambil dengan menggunakan proporsional pada setiap kelompok yang dijadikan populasi dengan pembagian sembilan sampel pada Kelompok Pindang Barokah, sembilan sampel pada Kelompok Minanggala, sembilan sampel pada kelompok pindang mandiri dan tujuh orang pada Kelompok Mina Sugih Tani. Pengumpulan data dilakukan dengan studi literature dan wawancara langsung dengan pelaku usaha. Analisis masalah dilakukan menggunakan Problem Tree Analysis.

\section{HASIL DAN PEMBAHASAN}

Sumber Daya Alam

Kecamatan Bantargadung seluas 15.061 Ha yang terdiri dari lahan pertanian (6.550 Ha), sawah (2.056 ha), bukan sawah (4.494 Ha) dan bukan pertanian (1.961 Ha). Lahan Basah seluas 968,6 Ha yang terdiri dari Sawah Berpengairan $1 / 2$ Teknis atau Pedesaan seluas 658,4 Ha, Berpengairan Tadah Hujan seluas 288,7 Ha dan Kolam seluas 21,5 Ha merupakan potensi yang dapat dikembangkan dan ditingkatkan produktivitasnya (Tabel 1).

Dari data primer yang didapatkan, jumlah luasan kolam yang terdapat di Desa Buanajaya baru termanfaatkan sebesar 1,9 Ha. Hal tersebut dikarenakan banyak kolam yang sudah tidak lagi digunakan atau pemilik kolam tersebut yang tidak lagi berkonsentrasi pada usaha budidaya sehingga kolam tidak termanfaatkan. Data luasan kolam di Desa Buanajaya pada tahun 2017 adalah sebesar $3 \mathrm{Ha}$. Dari data tersebut dapat diartikan bahwa masih ada kolam yang dapat dikembangkan untuk potensi perikanan budidaya. Disamping itu, adanya sawah juga berpotensi untuk dikembangkannya minapadi kolam dalam. Hasil kajian Lantarsih (2016) tentang pengembangan minapadi kolam dalam pada petani padi sawah di Kabupaten Sleman, Jawa Tengah, menyebutkan bahwa dengan 
Tabel 1. Luas lahan sawah dan kolam di Kecamatan Bantargadung tahun 2017

\begin{tabular}{llccccc}
\hline No & \multicolumn{1}{c}{ Desa } & $\begin{array}{c}\text { Pengairan } \\
\text { 1/2 Teknis } \\
\mathbf{H a}\end{array}$ & $\begin{array}{c}\text { Pengairan } \\
\text { Tadah } \\
\text { Hujan (Ha) }\end{array}$ & $\begin{array}{c}\text { Jumlah } \\
\text { Sawah } \\
\mathbf{( H a )}\end{array}$ & $\begin{array}{c}\text { Kolam } \\
\mathbf{( H a )}\end{array}$ & $\begin{array}{c}\text { Jumlah } \\
\text { Lahan } \\
\text { Basah (Ha) }\end{array}$ \\
\hline 1 & Bantargadung & 89,0 & 48,0 & 137,0 & 2,0 & 139,0 \\
2 & Bantargebang & 142,0 & 52,0 & 194,0 & 7,0 & 201,0 \\
3 & Mangunjaya & 10,0 & 58,1 & 68,1 & 1,0 & 69,1 \\
4 & Boyongsari & 80,0 & 20,0 & 100,0 & 2,0 & 102,0 \\
\hline 5 & Buanajaya & 100,0 & 25,0 & 125,0 & 3,0 & 128,0 \\
6 & Bojonggaling & 179,4 & 15,8 & 195,0 & 2,5 & 197,5 \\
7 & Limusnunggal & 58,0 & 70,0 & 128,0 & 4,0 & 132,0 \\
\hline & Jumlah & $\mathbf{6 5 8 , 4}$ & $\mathbf{2 8 8 , 7}$ & $\mathbf{9 4 7 , 1}$ & $\mathbf{2 1 , 5}$ & $\mathbf{9 6 8 , 6}$ \\
& \% & $\mathbf{6 8 , 0}$ & $\mathbf{2 9 , 8}$ & $\mathbf{9 7 , 8}$ & $\mathbf{2 , 2}$ & \\
\hline
\end{tabular}

Sumber: Monografi Kecamatan Bantargadung, 2017

menerapkan budidaya minapadi kolam dalam, terjadi peningkatan produksi ikan dan produksi padi, pendapatan petani, terhambatnya pertumbuhan gulma, terhambatnya pertumbuhan hama, peningkatan kesuburan tanah, kemampuan untuk menjaga kelestarian lingkungan alam, motivasi petani dalam berusaha.

\section{Sumber Daya Manusia}

Tingkat penerapan adopsi dan inovasi selain dipengaruhi oleh usia, dipengaruhi juga oleh tingkat pendidikan. Semakin tinggi pendidikan, maka penerapan adopsi dan inovasi semakin cepat. Penduduk berdasarkan tingkat pendidikan disajikan pada Tabel 2.

Tingkat pendidikan di Kecamatan Bantargadung masih rendah (Tabel 2).
Hal tersebut dapat terlihat dari tingkat pendidikan warga yang masih didominasi oleh tamatan SD sebanyak $44,3 \%$ dari jumlah penduduk dibandingkan dengan tamatan SLTP $(32,4 \%)$ dan perguruan tinggi $(0,3 \%)$. Rendahnya tingkat pendidikan penduduk di Kecamatan Bantargadung tentunya juga berpengaruh pada penerapan adopsi inovasi yang selanjutnya juga berpengaruh pada pengembangan bidang perikanan. Hal ini sesuai dengan penelitian Restu (2008) yang mengatakan bahwa biasanya petani ataupun pelaku usaha perikanan yang mendapat pendidikan hanya hingga tingkat sekolah dasar tidak memperhitungkan risiko yang diambil dalam melakukan usaha. Selain itu berdasarkan hasil kajian Hermawan, Amanah, dan Fatchiya (2017), juga 
Tabel 2. Penduduk berdasarkan tingkat pendidikan di Kecamatan Bantargadung tahun 2016

\begin{tabular}{llcccccc}
\hline No & \multicolumn{1}{c}{ Desa } & $\begin{array}{c}\text { Jumlah } \\
\text { Penduduk } \\
\text { (Orang) }\end{array}$ & $\begin{array}{c}\text { Belum } \\
\text { /Tidak } \\
\text { Sekolah } \\
\text { (Orang) }\end{array}$ & $\begin{array}{c}\text { Lulus } \\
\text { SD } \\
\text { (Orang) }\end{array}$ & $\begin{array}{c}\text { Lulus } \\
\text { SLTP } \\
\text { (Orang) }\end{array}$ & $\begin{array}{c}\text { Lulus } \\
\text { SLTA } \\
\text { (Orang) }\end{array}$ & $\begin{array}{c}\text { Lulus } \\
\text { Perguruan } \\
\text { Tinggi } \\
\text { (Orang) }\end{array}$ \\
\hline 1 & Bantargadung & 8.599 & 323 & 3.711 & 2.862 & 1.682 & 21 \\
\hline 2 & Bantargebang & 3.835 & 134 & 1.747 & 1.276 & 665 & 13 \\
3 & Mangunjaya & 3.352 & 202 & 1.451 & 1.044 & 646 & 10 \\
4 & Boyongsari & 3.623 & 278 & 1.457 & 1.081 & 788 & 19 \\
\hline 5 & Buanajaya & 3.053 & 123 & 1.360 & 1.003 & 550 & 17 \\
\hline 6 & Bojonggaling & 7.591 & 380 & 3.405 & 2.469 & 1.319 & 18 \\
7 & Limusnunggal & 6.088 & 244 & 2.879 & 1.958 & 995 & 12 \\
\hline & Jumlah & $\mathbf{3 6 . 1 4 1}$ & $\mathbf{1 . 6 8 3}$ & $\mathbf{1 6 . 0 1 0}$ & $\mathbf{1 1 . 6 9 3}$ & $\mathbf{6 . 6 4 5}$ & $\mathbf{1 1 0}$ \\
\hline
\end{tabular}

Sumber: UPTD Pendidikan, 2016

menyatakan bahwa tahap pengambilan keputusan dari kelompok pembudidaya dipengaruhi oleh tingkat pendidikan formal dan tingkat pendidikan non formal.

\section{Potensi Produksi Perikanan}

Kecamatan Bantargadung hanya ada empat kelompok perikanan yang terbentuk yang terdiri dari tiga kelompok pengolah dan satu kelompok budidaya ikan yang terdapat di Desa Bantargadung dan Desa Buanajaya. Proses produksi perikanan yang terdapat di Kecamatan Bantargadung meliputi produksi budidaya perikanan dan pengolahan hasil perikanan.

\section{Gambaran potensi perikanan} dapat dilihat pada Tabel 3. Dari empat kelompok, diambil sampel sebanyak tujuh sampel dari segmen budidaya dan 27 sampel dari segmen pengolahan perikanan. Data produksi hasil identifikasi pada Tabel 4.

Pada Tabel 3 dan Tabel 4 dapat dilihat perbedaan antara luas atau unit maupun produksi per tahun pada data yang di dapat dari BP3K dengan data primer. Adanya perbedaan pada luas lahan maupun unit yang ada pada data sekunder dengan data primer diakibatkan karena data primer merupakan penghitungan dari populasi yang diambil dari kelompok. Data Tabel 3 dan Tabel 4 di atas memperlihatkan peningkatan produksi per-unit usaha dari tahun 2017 ke tahun 2018, untuk usaha budidaya ikan di kolam dari $0,6 \mathrm{~kg} \cdot \mathrm{m}^{-2}$ menjadi $2,74 \mathrm{~kg} \cdot \mathrm{m}^{-2}$ atau naik $474 \%$; serta untuk usaha pengolahan pindang 
Tabel 3. Produksi perikanan darat Kecamatan Bantargadung tahun 2017

\begin{tabular}{llcc}
\hline No & \multicolumn{1}{c}{ Jenis Usaha } & Luas/jumlah & Produksi (kg) \\
\hline 1 & Kolam Air Tenang (KAT) & $20.500 \mathrm{~m}^{2}$ & 12.300 \\
2 & Pengolahan Hasil lkan (Pindang) & 150 unit & 600.000 \\
\hline
\end{tabular}

Sumber: BP3K Bantargadung, 2017

Tabel 4. Produksi perikanan sampel budidaya dan pengolahan

\begin{tabular}{llcc}
\hline No & \multicolumn{1}{c}{ Jenis Usaha } & Luas/Jumlah & Produksi $(\mathbf{k g})$ \\
\hline 1 & Budidaya & $19.885 \mathrm{~m}^{2}$ & 54.432 \\
2 & Pengolahan Pindang Ikan & 90 Unit & 817.440 \\
\hline
\end{tabular}

Sumber: Data Primer, 2018

ikan dari 4.000 kg.unit ${ }^{-1}$ menjadi 9.082 kg.unit $^{-1}$ atau naik $227 \%$. Hal ini menunjukkan adanya peningkatan produksi perikanan yang signifikan di wilayah Kecamatan Bantargadung. Menurut Hamidi, Ningsih, dan Sari (2011) peningkatan produksi yang terjadi, dapat disebabkan oleh intensifikasi melalui berbagai aktivitas perikanan yang sudah ada.

\section{Potensi Usaha Perikanan}

Segmentasi usaha yang ada di Kecamatan Bantargadung adalah budidaya pembesaran lele dan nila, pembenihan lele, dan pengolahan pindang ikan. Input usaha meliputi modal, tenaga kerja, lokasi serta bahan baku. Modal usaha pengolahan maupun pembudidaya merupakan modal pribadi. Sesekali pemerintah melalui Dislutkan sukabumi memberikan bantuan berupa indukan, benih, serta peralatan pengolahan. Pelaku usaha baik pengolah dan pembudidaya tidak menggunakan tenaga kerja dalam menjalankan usahanya. Hanya saja pembudidaya menggunakan tenaga kerja pada saat panen dan perbaikan kolam. Input berupa benih didapatkan dari pembenih di sekitar daerah utara Sukabumi dan dari kelompok untuk benih lele. Sedangkan indukkan lele berasal dari BPBIAT Sukabumi yang merupakan bantuan dari Dislutkan Sukabumi. Bahan baku ikan yang digunakan dalam proses pemindangan didapatkan dari TPI Palabuhanratu dan Muara Baru. sarana dan prasarana lainnya didapatkan dari saproktan maupun saprokan di sekitar Kecamatan Bantargadung. Proses produksi budidaya maupun pengolahan pindang masih dijalankan secara konvensional. Selain itu, proses produksi belum sesuai dengan standar yang berlaku. 
Tabel 5. Rataan kelayakan analisis usaha budidaya dan pengolahan

\begin{tabular}{rlrcccccc}
\hline No & Usaha & Pendapatan & Laba & BEP (RP) & $\begin{array}{c}\text { BEP } \\
\text { (Unit) }\end{array}$ & PP & R/C & $\begin{array}{c}\text { ROI } \\
\text { (\%) }\end{array}$ \\
\hline 1 & Budidaya & 9.185 .571 & 4.585 .202 & 9.485 .789 & - & 3,2 & 2,0 & 49,7 \\
2 & Pengolahan & 24.664 .444 & 7.155 .164 & 5.859 .140 & 1.100 & 0,5 & 1,43 & 246,97 \\
\hline
\end{tabular}

Sumber: Data Primer, 2018

Tabel 6. Pendapatan terhadap usaha tani di Kecamatan Bantargadung tahun 2017

\begin{tabular}{llcccc}
\hline No. & Nama Desa & $\begin{array}{c}\text { Jumlah } \\
\text { KK } \\
\text { Seluruh }\end{array}$ & $\begin{array}{c}\text { Jumlah KK } \\
\text { Tani } \\
(\text { KK) }\end{array}$ & $\begin{array}{c}\text { Jumlah } \\
\text { Sampel }\end{array}$ & $\begin{array}{c}\text { Rata-rata } \\
\text { Pendapatan(Rp) }\end{array}$ \\
\hline 1. & Bantargadung & 2.688 & 1.397 & 245 & $1.741 .306,-$ \\
2. & Bantargebang & 1.169 & 861 & 166 & $2.073 .765,-$ \\
3. & Mangunjaya & 975 & 755 & 190 & $1.803 .605,-$ \\
4. & Boyongsari & 1.063 & 768 & 175 & $1.568 .200,-$ \\
5. & Buanajaya & 848 & 648 & 200 & $2.534 .275,-$ \\
6. & Bojonggaling & 2.310 & 1695 & 175 & $3.071 .257,-$ \\
7. & Limusnunggal & 1.698 & 1.304 & 150 & $2.282 .780,-$ \\
\hline Jumlah & 10.751 & 7.428 & 1.301 & $15.075 .188,-$ \\
\hline \multicolumn{7}{l}{} & Rata-rata & 69,1 & 17,5 & $2.153 .598,-$ \\
\hline
\end{tabular}

Sumber: Programa BP3K Kec. Bantargadung, 2018

Benih yang dijual adalah benih dengan ukuraran 5-7 cm yang dijual dengan harga Rp.200 setiap ekor. Sedangkan untuk ukuran konsumsi size 8-10 dijual dengan harga Rp. 18.000.kg 1. Pemasaran untuk pengolahan pindang langsung pada konsumen di daerah Sukabumi, Cianjur dan Bogor. Sedangkan untuk pembenihan dan pembesaran daerah pemasarannya adalah pasar sekitar Kecamatan Bantargadung dan daerah utara Kabupaten Sukabumi. Rataan analisis kelayakan usaha budidaya dan pengolahan pindang disajikan pada Tabel 5.

Berdasarkan Tabel 5 dan Tabel 6 dapat dilihat perbandingan antara pendapatan kotor usaha tani dengan usaha perikanan memiliki perbedaan yang cukup signifikan. Perbedaan siklus juga menyebabkan perbedaan pendapatan antara usaha tani dan usaha perikanan. Pada usaha perikanan, dalam hal ini pengolahan pindang ikan dibanding budidaya perikanan; dinilai lebih pengolahan pindang ikan menjanjikan dan layak untuk dijalankan. 
Data Tabel 5 memperlihatkan laba yang diperoleh pada usaha pengolahan pindang sebesar Rp 7.155.164, dibanding laba pada usaha perikanan budidaya yang tercatat sebesar $\mathrm{Rp}$ 4.585.202; atau lebih besar 156\%. Pilihan usaha yang lebih menguntungkan akan mampu meningkatkan pendapatan dan meningkatkan kesejahteraan masyarakat Kecamatan Bantargadung.

\section{Kondisi Aktivitas Penyuluhan Perikanan}

Pelaku utama dan pelaku usaha perikanan yang berada di Kecamatan Bantargadung merupakan sasaran penyuluhan. Penyuluh perikanan di Kabupaten Sukabumi terdiri dari 11 Penyuluh PNS dan 11 Penyuluh Non PNS, serta penyuluh di Kecamatan Bantargadung hanya satu orang yang juga membina wilayah kecamatan lain di Kabupaten Sukabumi. Ruang lingkup pembinaan yang dilakukan dengan mengacu kepada Pedoman Penumbuhkembangan kelembagaan pelaku utama (KepMen KP No 14 2012; Perpres No 154 2014). Hal ini menyebabkan kegiatan penyuluhan kurang maksimal dikarenakan sangat terbatasnya penyuluh dengan cakupan wilayah yang cukup luas. Penyuluhan dilakukan dengan alat peraga penyuluhan. Alat peraga penyuluhan yang dimiliki antara lain; barang cetakan berupa pamflet, leaflet, folder, brosur, platcard, poster sebanyak empat buah dengan pengadaan sebanyak sekali dalam setahun dengan kondisi baik; gambar terproyeksi berupa tranparansi dan film slide sebanyak masing-masing satu dengan pengadaan satu kali dalam setahun. Pembiayaan penyuluhan melalui APBN, APND baik provinsi maupun kabupaten kota.

\section{Analisis Masalah}

Analisis masalah dilakukan dengan menetapkan permasalahan adalah Tree Analysis menurut Ericson (1999). Setelah dianalisis, maka ditemukan akar permasalahan mengenai permasalahan teknis, ekonomi dan sosial. Permasalahan dari aspek teknis antara lain: kurangnya: pengetahuan, keterampilan dan sikap (PKS) mengenai penerapan sanitasi hygiene dan GMP (Good Manufacturing Procedure); kurangnya PKS dalam pencegahan hama melalui penerapan biosecurity, hal ini umum terjadi di lokasi pengolahan perikanan tradisonal. sebagaimana juga disampaikan dalam kajian Masrifah et al. (2015) terhadap penanganan sanitasi pengolahan pindang bandeng di Kabupaten Bogor, Jawa Barat. Terlihat juga kurangnya persiapan wadah yang sesuai CBIB, formulasi pakan mandiri yang belum sesuai dan belum efektif, dan penerapan teknologi budidaya. Permasalahan dalam aspek usaha 
antara lain modal belum maksimal hal tersebut disebabkan karena kurangnya pengetahuan mengenai peminjaman modal; pendapatan belum maksimal dikarenakan kurangnya PKS mengenai pengembangan variasi produk. Permasalahan dalam aspek sosial yaitu dinamika kelompok yang belum berjalan maksimal hal tersebut dikarenakan kurangnya pemaahaman pelaku usaha dan pelaku utama mengenai pentingnya berkelompok, serta kurangnya koordinasi antara-pelaku usaha dan pelaku utama sehingga pengembangan kelompok tidak meluas.

\section{SIMPULAN DAN SARAN}

Kecamatan Bantargadung seluas 15.061 Ha yang terdiri dari lahan pertanian (6.550 Ha), sawah (2.056 ha), bukan sawah (4.494 Ha) dan bukan pertanian (1.961 Ha). Lahan Basah seluas 968,6 Ha yang terdiri dari Sawah Berpengairan $1 / 2$ Teknis atau Pedesaan seluas 658,4 Ha, Berpengairan Tadah Hujan seluas 288,7 Ha dan Kolam seluas 21,5 Ha merupakan potensi yang dapat dikembangkan dan ditingkatkan produktivitasnya. Potensi perikanan yang mungkin untuk dikembangkan adalah Pengolahan Ikan Pindang serta budidaya ikan air tawar.

\section{DAFTAR PUSTAKA}

Amanah, Siti. 2008. "Sistem Penyuluhan Perikanan Dalam Mengantisipasi Era Perubahan." Jurnal Penyuluhan 4(2):139-51.

Ericson, Clifton A. 1999. "Fault tree analysis." Hal. 1-9 in System Safety Conference, Orlando, Florida. Vol. 1. Orlando (US).

Hamidi, Wahyu, Rahmita B. Ningsih, dan Mayang Sari. 2011. "Kontribusi sektor perikanan dalam peningkatan perekonomian Provinsi Riau." Jurnal Ekonomi 19(02).

Hermawan, Aan, Siti Amanah, dan Anna Fatchiya. 2017. "Partisipasi Pembudidaya Ikan dalam Kelompok Usaha Akuakultur di Kabupaten Tasikmalaya." Jurnal Penyuluhan 13(1):1-13.

KepMen KP No 14. 2012. Keputusan Menteri Kelautan dan Perikanan tentang Pedoman Umum Penumbuhan dan Pengembangan Kelembagaan Pelaku Utama Perikanan.

Lantarsih, Retno. 2016. "Pengembangan 'Minapadi Kolam Dalam' di Kabupaten Sleman." AGRARIS: Journal of Agribusiness and Rural Development Research 2(1):17-27.

Perpres No 154. 2014. Peraturan Presiden tentang Kelembagaan Penyuluhan Pertanian, Perikanan, dan Kehutanan. Indonesia. 
Restu, A. 2008. "Pengaruh Pengawasan

Terhadap Disiplin Kerja Pegawai Negeri Sipil Pada Kantor Sekretariat pada Kabupaten Serdang Bedagai [Skripsi]." Universitas Sumatera Utara.

Rosidawanti, Dini, Unang Yunasaf, dan

Syahirul Alim. 2015. "Penggunaan Media Informasi dan Teknologi Sebagai Sumber Informasi Penyuluhan di Bidang Peternakan." Student e-Journals 4(2). 